\title{
Teaching kinematic graphs in an undergraduate course using an active methodology mediated by video analysis
}

\author{
Riikka-Liisa Vaara ${ }^{1}$ and Daniel Guilherme Gomes Sasaki \\ ${ }^{1}$ Tampere University of Applied Sciences (TAMK), Tampere, Finland \\ ${ }^{2}$ Centro Federal de Educação Tecnológica Celso Suckow da Fonseca CEFET-RJ/Unidade Maracanã, \\ Rio de Janeiro, RJ, Brazil
}

This work address the preconceptions of first year engineering students about the kinematic graphs and the outcomes of a pedagogical strategy that relies on Predict - Observe - Explain learning method mediated by a video analysis software. The whole learning procedure was accompanied by a written material as students' worksheets which enabled a formal record of the students' conceptions throughout the process. The Test of Understanding of Kinematics Graphs was utilized to evaluate the students' preconceptions and learning gains. It was found that first year engineering students had serious difficulties in drawing and interpreting kinematic graphs. Although interpretation of graphs and the understanding of the velocity and acceleration concepts improved, the preconceptions were quite resilient.

Keywords: physics education, active learning methodology, POE, video analysis, kinematic graphs
Article details

LUMAT General Issue Vol 7 No 1 (2019), 1-26

Received 9 December 2018 Accepted 23 January 2019 Published 4 February 2019

Pages: 26

References: 24

Contact: r.I.vaara@gmail.com

https://doi.org/10.31129/ LUMAT.7.1.374

\section{Introduction}

Physics is a science that in essence is the result of the inseparable balance between theory and experimentation. This fact has also been seen as the basis for physics education. However, it has commonly adopted in the undergraduate courses a reductionist approach by characterizing the experiments as a mere illustration of the theory, usually with the objective of 'proving' a law learned in a theory class (Tamir, 1989). Hodson (1988) has pointed out that, as a consequence, the student tends to exaggerate the importance of his/her experimental results, in addition to giving rise to a misunderstanding between theory and observation. Another aspect is that students soon realize that their experiment should produce the expected result of the theory, or that some regularity should be found. When they do not get the expected response, they are baffled with this error, and if they realize that the 'error' can affect their grades, they intentionally change the observations and data to get the 'correct answer'. In order to tackle this issue, Arons (1993) has suggested a redesign of traditional laboratory to provide a guided insight and inquiry method where students are encouraged to ask themselves throughout the experiment some critical thinking 
questions, such as: How do we know...? What is the evidence for...? What will happen if...?

Tamir (1991) has proposed the categorization of investigative activities in four levels. At level o, which roughly corresponds to a complete closed problem, the problem, the procedures and what is desired to be observed is provided by the teacher, being left to the students just to collect data and confirm or not the conclusions. At level 1, the problem and procedures are defined by the teacher, through a guide, for example. The student is responsible for collecting the indicated data and obtaining the conclusions. At level 2, only the situation-problem is given, allowing the student to decide how and what data to collect, to take the required measurements and to draw conclusions from them. Finally, at level 3, the most open level of research, the student must do everything from formulating the problem to reaching the conclusions.

According to Hofstein and Lunetta (2004), in their review about Laboratory in Science Education, the laboratory guides generally encourages the 'cookbook approach', where the students are divided into small groups, receive the equipment and perform the experiment guided by scripts that must be followed step-by-step. Such scripts in the experimental classes simply aim to determine the measure of physical quantities or parameters and its comparison with a known value excluding previous conceptions, historical contextualization, construction of concepts, limitations of established models and ultimately the scientific method (Tamir, 1989). Some merits of this kind of activity must be acknowledged, for example, the students are recommended to interact with each other in teams and to work with specific instruments and experimental setups. However, the main criticism of these practical activities is that they do not engage students in thinking about the larger purposes of their investigation and of the sequence of tasks they need to pursue to achieve those ends (Hofstein, \& Lunetta, 2004). Unfortunately, this model of teaching of experimental activities is still widely used today despite numerous discussions about its ineffectiveness as illustrated recently (Holmes, Olsen, Thomas, \& Wieman, 2017).

Alternative, the Predict - Observe - Explain (POE) methodology has been used as a strategy to promote learning in physics and chemistry (Haysom \& Bowen, 2010). It has been indicated the efficiency of this method with computer simulations (Chase, Shemwell, \& Schwartz, 2010; Hussain et al, 2013; Tao \& Gunstone, 1999) and videos (Kearney, 2004). The POE method was created by Champagne, Klopfer and Anderson (1980) under the name of Demonstrate - Observe - Explain (DOE). It was originally developed as a tool for formative assessment. Subsequently the idea was reformulated 
to POE by two constructivist Australian researchers Richard White and Richard Gunstone (1992). In the first stage of this method, in the prediction, the learners' previous conceptions on a specific theme are elicited and their intuitive and unspoken ideas are made explicit. The students are asked to make predictions about an experimental situation and justify them according to their knowledge. This stage can also be considered as a diagnostic tool for skills not related to the curriculum, because in addition to previous conceptions, it provides the teacher with data about the students' ability to express and organize ideas. Generally, in this stage students are told to be "sincere, write only what they think and do not worry about giving the correct answer", since none of the tasks in the POE method is subject to summative evaluation. Then in the second stage the students will perform and/or observe the experiment. Finally, in the third stage corresponding to the explanation the students should try to explain the possible discrepancies between their predictions and what was observed in the experimental demonstration.

It is expected that when applying the POE methodology, discrepancies arise between the predictions and observations, so that students can discuss the hypotheses raised and with the teacher's help become aware of the conceptions that led them to such hypotheses. It is important that the teacher is careful to construct situations that promote the contrast between the student's prior knowledge and observations, but it is also important to provide situations that confirm the intuitive response. This balance should be designed so that students do become encouraged and realize that they are also capable of creating models that are in accordance with current scientific thinking.

The theoretical foundation that inspired the POE methodology is undoubtedly the concept of cognitive conflict arising from theory of equilibration of cognitive structures by Piaget (1985). Hence, when cognitive conflict occurs the learner initially seeks to establish the so-called assimilation of the observed phenomena to his mental structure of models. If this assimilation is not feasible because of the inconsistencies between its model and reality, then there is an imbalance, that is, a situation of conflict in conceptual structures. In order to re-establish another balance that explains the discrepant situation, a cognitive effort is required to modify, add and construct new structures of thought, called accommodation. The mechanism of equilibration occurs through three behaviours: the alpha, which consists the attempt to neutralize the disturbance, ignoring it, rejecting it or removing it from any reflection. The beta behaviour aims to integrate the disturbance in the thinking system, through a 
reinterpretation of the anomalous results or the elaboration of ad hoc hypotheses. Finally, the gamma behaviour is characterized by the rescue of the balance through a conceptual change. The POE methodology is an active learning method that intends developing this last type of behaviour.

The present work intends to search for evidences that can clarify the following question of investigation: is the use of a pedagogical sequence that relies on the above mentioned POE learning method mediated by free video analysis software an efficient strategy to improve the learning of kinematic graphs? By means a validated and wellestablished survey we report the preconceptions of first year engineering students concerning the kinematics graphs and eventually compare these preconceptions with the outcomes of the POE method. Besides, a qualitative analysis of students' worksheets provides some insights concerned about the students reasoning along the practical activities.

\section{Methodology}

\subsection{Target audience}

The study was conducted in two Mechanics courses for engineering students at a University of Applied Sciences. A very important part of the objectives in an undergraduate mechanics course is that students learn to draw and interpret kinematics graphs and properties starting from some basic rectilinear motions. There were about 30 first year engineer students in both courses $(\mathrm{N}=61)$. The students were divided into small groups with about four students per a group. Students were graduated either from Finnish upper secondary schools or vocational schools, and some physical concepts and definitions such as velocity and acceleration were familiar to them from their previous studies.

\subsection{Instruments for evaluating learning gains}

First of all, discussions and POE worksheets filled by students, which contained their predictions, observations and explanations for every experiment, provided an important material to qualitative analysis about students' preconceptions and reasoning progress throughout the lessons.

Secondly, the Test of Understanding of Kinematics Graphs (TUG-K) by Beichner (1994) was applied in the beginning of the course and after the last kinematics lesson 
in order to evaluate students learning gains. Although this test is quite old, it is widespread and a common tool for testing students, thus it is possible to compare the results with existing literature. The TUG-K has been used in different kind of studies, for instance to evaluate the effectiveness of new curricular material (Zavala, Tejeda, Barniol, \& Beichner, 2017). It has been shown that TUG-K has content validity and is a reliable test of understanding of kinematics graphs for groups of high school and college level students taking introductory physics (Beichner, 1994). In fact, Beichner has taken 524 high-school and college students to produce a robust statistics using standard parameters, such as (i) KR-20 the Kuder-Richardson coefficient to measure the reliability of the whole test via calculation of the internal consistency of the items (ii) the Point-biserial Coefficient related to the reliability of a single test item, defined as the correlation between the item's correctness and the whole test score and (iii) the Ferguson's Delta to discriminate ability of the whole test via how broadly it spreads the distribution of scores. In this work no statistical validation could be provided because the number of students involved is rather small. However, we can assume the reliability of TUG-K in our context because the similarity between students' profiles.

We also tested our control group $(\mathrm{N}=30)$ taught by lecturing for comparison. The control group consisted of very similar students as the experimental groups. The teaching schedule and homework were also similar but the lessons were instructorcentered presentations without group working and experimental tasks.

The TUG-K test contains 21 multiple choice questions that address graphs of position, velocity and acceleration as a function of time, and tasks related to determining slope of lines and areas, as well as understanding the connection between different graphs. The TUG-K survey is not available here because it would entail to loss of effectiveness if students were aware of the questions and respective answer key. The survey can only be accessed by registered researchers through a password on the Physport website (2019). The test concentrates on the typical misconceptions of students at all levels when interpreting kinematics graphs. According to Beichner (1994) the misconceptions can be briefly presented as follows:

1. Graphs as motion pictures: The graph is considered to be like a photograph of the situation. It is not seen to be an abstract mathematical representation, but rather a concrete duplication of the motion event.

2. Slope/Height Confusion: Students often read values off the axes and directly assign them to the slope. 
3. Variable Confusion: Students do not distinguish between distance, velocity, and acceleration. They often believe that graphs of these variables should be identical and appear to readily switch axis labels from one variable to another without recognizing that the graphed line should also change.

4. Non-origin Slope Errors: Students successfully find the slope of lines which pass through the origin. However, they have difficulty determining the slope of a line (or the appropriate tangent line) if it does not go through zero.

5. Area Ignorance: Students do not recognize the meaning of areas under kinematics graphs curves.

6. Area/Slope/Height Confusion: Students often perform slope calculations or inappropriately use axis values when area calculations are required.

In addition, normalized gain introduced by Haake (1998) was calculated for both the POE experimental group and the control group taught by lecturing. The normalized gain was calculated by the formula:

$$
\langle g\rangle=\frac{\left\langle R_{f}\right\rangle-\left\langle R_{i}\right\rangle}{100-\left\langle R_{i}\right\rangle}
$$

where $\mathrm{R} i / f$ are the initial and final score. The normalized gain can be considered as a rough measure of the effectiveness of a course in promoting learning.

\subsection{Implementation of the lessons}

It was adopted a version of POE methodology that followed Haysom and Bowen protocol (2010). Therefore, all lessons proceeded as follows:

1. Orientation and motivation: Arousing student's interest and curiosity about class subject through challenging question, videos or simulations.

2. Introduction: Presentation of an experiment, explaining its objectives and operation without executing it.

3. Prediction: Elicitation of student's previous ideas. Students write their predictions about the outcome of the experiment individually and justify their predictions in the worksheets. This procedure makes the students more aware of their own thoughts. It has also been suggested that the prediction 
engages students to make observations (Crouch, Fagen, Callan, \& Mazur, 2004). In addition, the worksheets containing the predictions serve as a valuable diagnostic assessment tool for the teacher.

4. Discussion predictions: Students are divided into small groups to discuss their predictions and justifications. It is a fundamental step where students will cooperate with each other to improve their predictions. At this stage, the teacher should only encourage participation and be supportive without intervention.

5. Observation: Students organized in small groups execute and film the experiment and describe what they observed. Afterward, they use a free video analysis tool, Tracker whose applications have also recently been introduced in the literature (De Jesus, 2017), to analyze the filmed experiment.

6. Explanation: Students confirm their predictions or seek out the reasons for any discrepancies between their predictions and the observation. The worksheets containing the explanations serve as a valuable tool for formative evaluation by the teacher.

7. Scientific explanation: The current scientific model of the phenomenon is presented by the teacher. The students' predictions and explanations are shared and debated, as well as their comments. Students are expected to write the new terms and ideas in the worksheets.

8. Follow-up: The previous ideas are extremely resilient, so it is important that the students resume their reflections between consecutive classes. We propose a sequence of exercises that intend to deepen, broaden and apply the concepts covered in the former class.

Table 1 shows the timetable for the classes including the subjects and the activities of the lessons, duration, equipment and homework. 
Table 1. Timetable: the subjects and the activities of the lessons, duration, equipment and homework.

\begin{tabular}{|c|c|c|c|}
\hline Lesson & Subjects and activities & Equipment & Homework \\
\hline 1 & $\begin{array}{l}\text {-TUG-K pre-test } 45 \text { min } \\
\text { - Measurement and graph } \\
\text { concepts and introducing } \\
\text { Tracker tool } 45 \text { min }\end{array}$ & $\begin{array}{l}\text { - Students' own } \\
\text { computers }\end{array}$ & $\begin{array}{l}\text { - Installing Tracker software } \\
\text { and getting to know the main } \\
\text { character of the program with } \\
\text { the video tutorials }\end{array}$ \\
\hline 2 & $\begin{array}{l}\text { - Horizontal motion } \\
\text { experiment on air track } \\
\text {-POE worksheets and video } \\
\text { analysis } 1,5 \mathrm{~h}\end{array}$ & $\begin{array}{l}\text {-Air track and a cart } \\
\text {-A level } \\
\text { - Students' own } \\
\text { smartphones, computers } \\
\text { - Tracker }\end{array}$ & \multirow[t]{2}{*}{$\begin{array}{l}\text { - Traditional calculations and } \\
\text { graphical tasks from textbooks } \\
\text { related to average and instant } \\
\text { velocity and acceleration, } \\
\text { gravitational acceleration, } \\
\text { slope and area calculation } \\
\text { from graphical presentations }\end{array}$} \\
\hline 3 & $\begin{array}{l}\text { - Free fall motion experiment } \\
\text {-POE worksheets and video } \\
\text { analysis } 1,5 \mathrm{~h}\end{array}$ & $\begin{array}{l}\text { - Marbles/balls } \\
\text { - Students' own } \\
\text { smartphones, computers } \\
\text {-Tracker }\end{array}$ & \\
\hline 4 & $\begin{array}{l}\text { - Motion on an inclined air } \\
\text { track -experiment } \\
\text {-POE worksheets and video } \\
\text { analysis } 1 \mathrm{~h}\end{array}$ & $\begin{array}{l}\text { - Air track and a cart } \\
\text { - Students' own } \\
\text { smartphones, computers } \\
\text { - Tracker }\end{array}$ & \multirow{2}{*}{$\begin{array}{l}\text { - Traditional calculations and } \\
\text { graphical tasks from textbooks } \\
\text { related to acceleration and } \\
\text { gravitational acceleration, } \\
\text { projectile motion, graphical } \\
\text { presentations }\end{array}$} \\
\hline 5 & $\begin{array}{l}\text { - Projectile motion experiment } \\
\text {-POE worksheets and video } \\
\text { analysis } 1 \mathrm{~h}\end{array}$ & $\begin{array}{l}\text { - Marbles/balls } \\
\text {-Students' own } \\
\text { smartphones, computers } \\
\text {-Tracker }\end{array}$ & \\
\hline 6 & -TUG-K post-test $45 \mathrm{~min}$ & $\begin{array}{l}\text {-Students' own } \\
\text { computers }\end{array}$ & \\
\hline
\end{tabular}

\subsection{Experimental tasks}

The students in small groups conducted experiments (stage 5) concerning the following four motions in this order according to the timetable (Table 1): horizontal motion on an air track, free falling motion, motion on an inclined air track and projectile motion. All experiments were supported by Tracker, a free video analysis software created in partnership with Open Source Physics (OSP), a worldwide community that contributes to the provision of free resources for physics teaching and computational modeling (Physlets, 2018). Tracker decomposes a video frame by frame allowing the study of various types of motion from videos made with digital cameras or smartphones. By means of this technology, physics teachers and students 
are able to develop experiments and laboratory activities of low cost, but of high academic quality. Tracker has an easy learning feature, which makes it relatively simple to use in obtaining relevant information in physics experiments.

In order to get students to be acquainted with the Tracker, it was provided instructions to install the software at their home. We gave the students a short tutorial for Tracker and we utilized the step by step beginner's guide videos on Tracker website. Furthermore, we instructed students in advance how to make a video: some attention was needed to small details such as calibration, lighting and camera stability to make the results of the videos as illustrative as possible. We tried to avoid overwhelming instruction which could cause the measurements to become a mechanical achievement for the students and decrease the students' enthusiasm to try and explore the software tools.

In every experiment students "tracked" the item by tagging a position in a video frame. Tracker automatically drew graphs of position, speed, and acceleration as a function of time based on the marked points. Additionally, it was possible to change the measurement points and coordinate axis in the video analysis to detect how the change affected on the graphs. Also students were able to find the slope of the fitted line with the analysis tools in Tracker, although the qualitative expression of the graphs was the main learning target. Afterwards, students outlined graphs yielded by Tracker in their POE worksheets and compared them with their own preliminary views.

\section{Results}

\subsection{Horizontal motion experiment}

It was chosen the horizontal motion as the first experiment for its simplicity and because students were already acquainted with it in their previous physics courses. The first assignment for students was to describe the motion of the cart on the horizontal air track by words and graphical presentation. They drew position, speed and acceleration as a function of time in accordance with their preconceptions, and also described by writing how the cart moves on the air track. They compared their preconceptions with each other in the small groups.

While studying the POE worksheets, we found that approximately $40 \%$ of the students $(\mathrm{N}=61)$ drew the horizontal motion graphs incorrectly according to their 
preconceptions when we asked students to draw the $(t, x)-,(t, v)$ - and $(t, a)$-graphs on the worksheets. Figure 1 shows some students' preliminary views on the subject.

a)
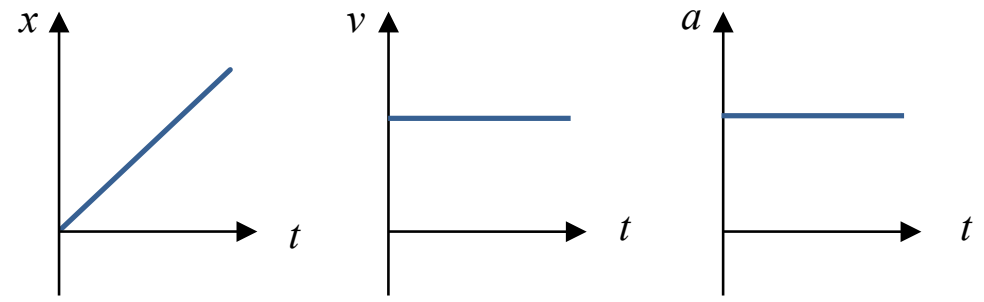

"The cart's speed and acceleration are constant."

$(12 \%)$

b)
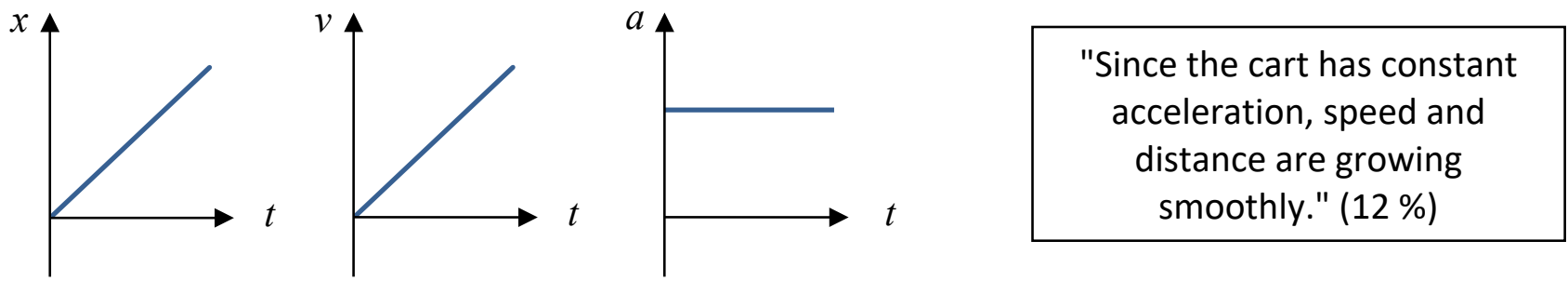

c)
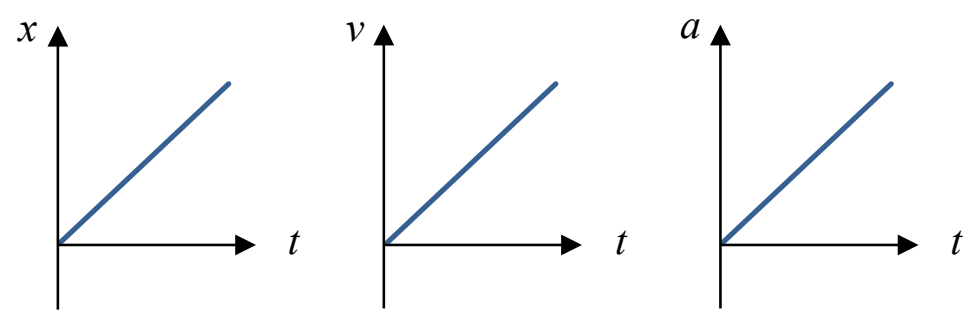

"The distance increases constantly at an accelerating speed." (5 \%)

d)
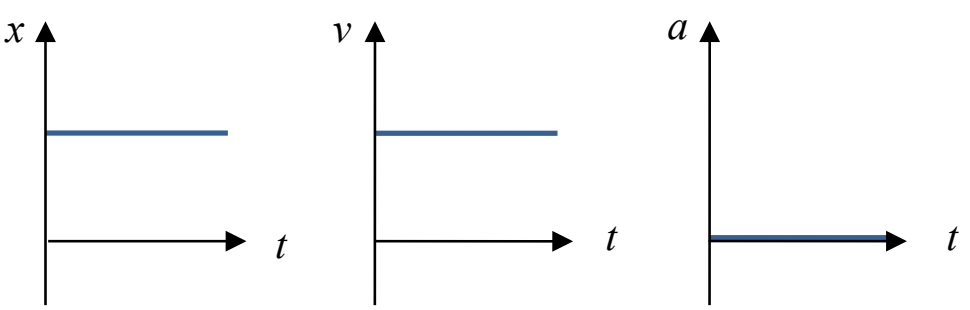

"The cart keeps moving at a constant speed." (5 \%)

Figure 1. Some preconceptions of the students about the horizontal motion of a cart on an air track. Graphs shown in a) and b) were the most popular false assumptions drawn by the students. The percentage of the students who drew these particular combination of the graphs and few selected verbal answers connected to the graphs are shown in the figures. $(N=61)$.

The percentage of the students who drew these particular combination of graphs and few selected verbal answers connected to the graphs are shown in the figure. Figures $1 \mathrm{a}$ and $1 \mathrm{~b}$ show the most typical misconceptions and related verbal comments. Mixing the acceleration and speed concepts is a commonly known problem (Trowbridge \& McDermott, 1980, 1981). As can be seen from the verbal answers in 
Figure 1, a large part of the 1st year engineering students mixed these concepts. Considering the misconceptions described by Beichner (1994), it is seen in Figure 1c, that few students do not distinguish distance, velocity and acceleration in the graphs and it is believed that graphs of these variables are identical: switching the axis labels from one variable to another do not change the graphed line. The pre-TUG-K results were in line with this perception. In addition, it can be seen from the responses of the students described in Figure $1 \mathrm{~d}$ that few students consider the graph like a photograph or as a concrete presentations of the motion event. Also TUG-K results (especially item 8 in the test) confirmed this conclusion: the horizontal line in the $(t, x)$-graph was interpreted as a motion at constant velocity or that the object in question would roll along a flat surface.

After documenting and discussing the preconceptions, the students videoed the horizontal motion on an air track and analyzed it with Tracker. Figure 2 shows an example of screenshot of a video and its analysis. Figure 2 shows the air track and the tracked position marks for the cart as well as the graphs drawn by the application based on the marks. It should be pointed out that in this particular example, there is a minor negative slope in the $(t, v)$-graph, which may have effect on the students' interpretation.

The students were able to change the axis of the graphs and to determine the slope of lines. According to the TUG-K a common mistake before the measurements was that students ignore the difference in scales when calculating the slope (speed /acceleration) of lines. With this feature, students learned that the slope of the line was changed when the scale was changed in the coordinate system. 
a)

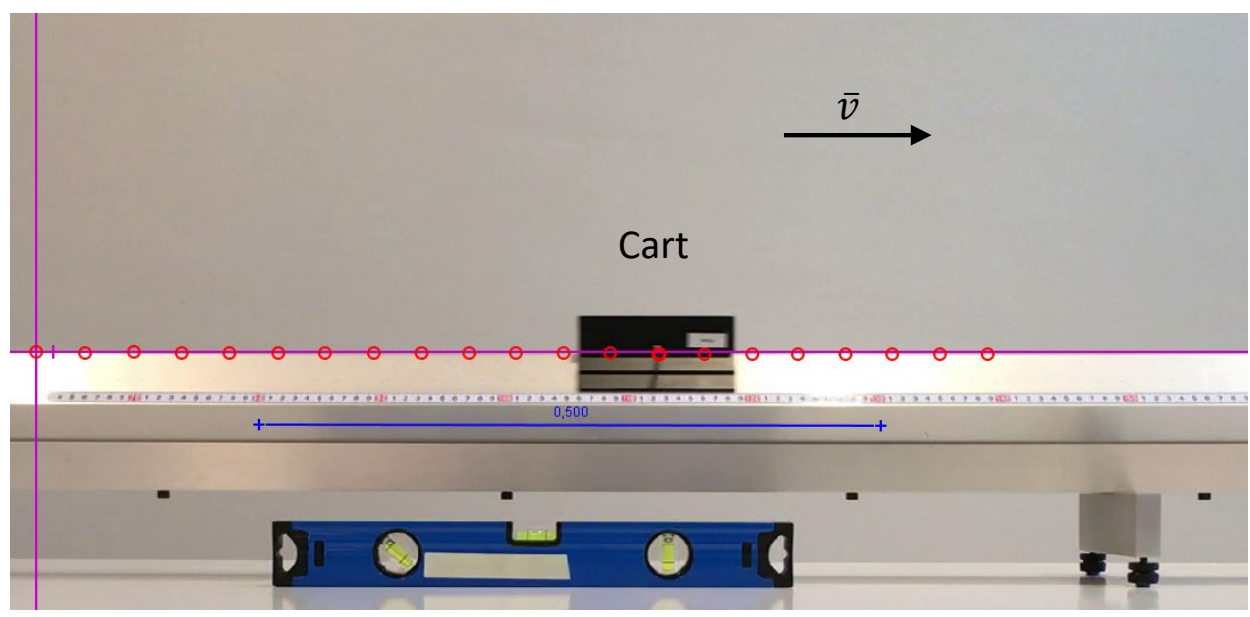

b)
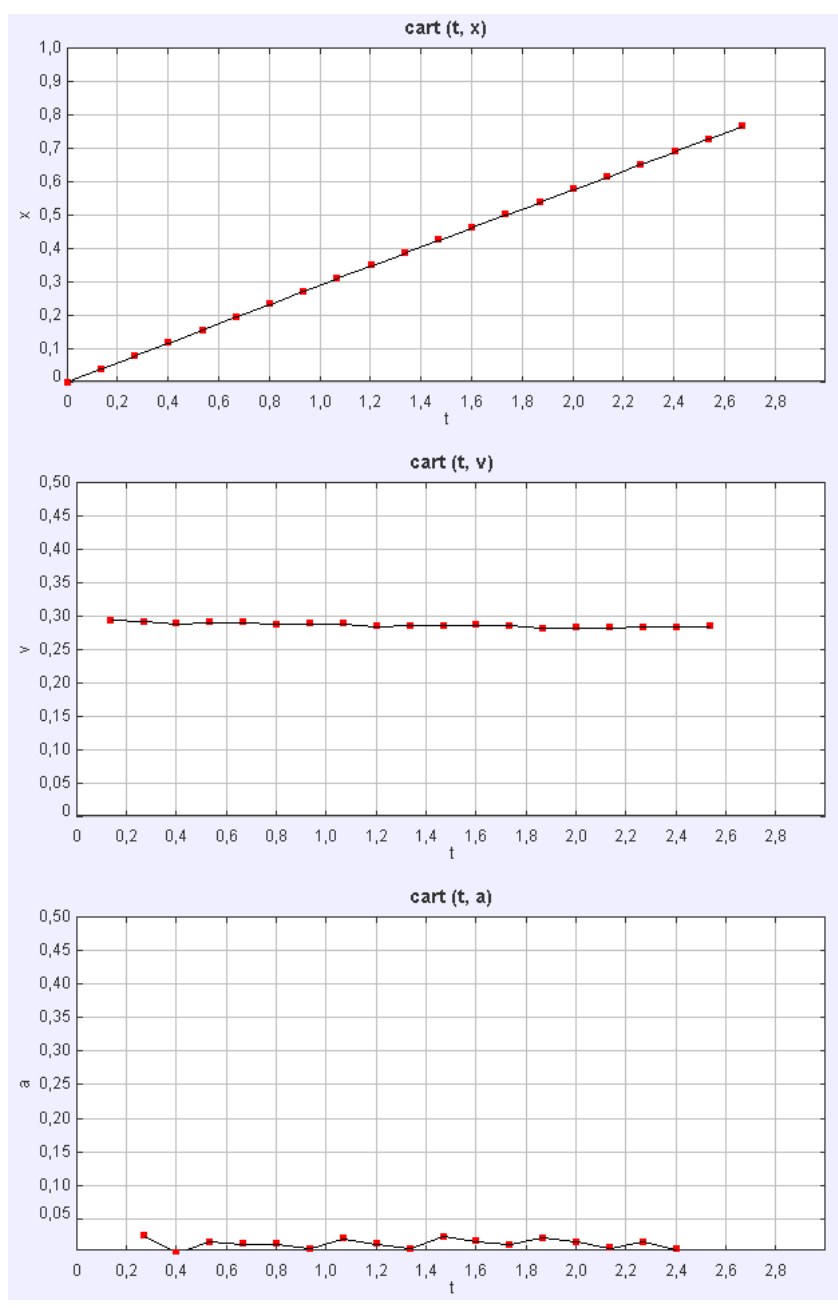

Figure 2. a) A screenshot from a tracked video showing the black cart moving smoothly on the horizontal air track from left to right and the tagged position points in the frames. A level was used to monitor for inclination of the plane to the horizon. A coordinate system (purple lines) and a known distance (blue line) for the calibration were set in the image. b) Graphs drawn by Tracker according to the tagged points: $(t, x)-,(t, v)$ - and $(t, a)$-graphs. 
Students determined the speed of the horizontal motion, as well as the acceleration in the free fall experiments, but otherwise Tracker graphs were used only for qualitative review. It would be very important to determine, besides the slope of lines, the area from the graphs. In this experiment, calculating the surface area was transferred to separate homework assignments due to the classroom time limitations, so Tracker graphs were not fully utilized.

Next, the students circulated their results and talked about the possible differences between the results and the preliminary concepts. Students who had a conflict between the results and the measurements were confused about the results they received. It was obvious that it was challenging to some students to confront their prediction when they found out that their prediction deviated from the correct answers. In-depth reflections were not presented by these students, although students were encouraged to reflect their own thinking and learning. The students were not eager to analyze the erroneous preconceptions but they briefly stated the contradiction between their preconceptions and results. It was also very difficult to the students to give any written explanations about the contradiction in the worksheets. On the other hand, students whose previous concepts were consistent with the measurements results defended their opinion and justified the results more eagerly. In addition, it is worthwhile to mention, that in the discussions students focused their attention especially on the measurements and technical details, such as Tracker's features and determining the speed of motion, not on the reflection of preconceptions.

At the next stage (stage 7) the scientific explanation was carried out in the class. The scientific model and mathematical formulas of the phenomenon was presented by the teacher. Also the students' predictions and explanations were debated, as well as their comments. The students' reflections showed the need to present exact mathematical formulas to the motion and "the right answers" for the graphs. They were also worried about the incorrect preconceptions on their worksheets, although it was emphasized that the worksheets will not be evaluated.

\subsection{The free fall motion experiment}

Figure 3 shows students' preliminary views and comments on the free fall motion. About $66 \%$ of the students had misconceptions. The most common misconception is shown in Figure 3 a. The verbal suggestions showed the aforementioned confusion 
between speed and acceleration. Also the word "constant" students used to mean, for instance, constant change.

Considering the misconceptions described by Beichner, it is seen in Figure 3c, that still about $10 \%$ of the students believed that graphs of distance, speed and acceleration are identical. This was supported by TUG-K results. It was seen from the students' responses that contrary to the case of the previous preconceptions students do not consider the graph as photographs anymore.

a)
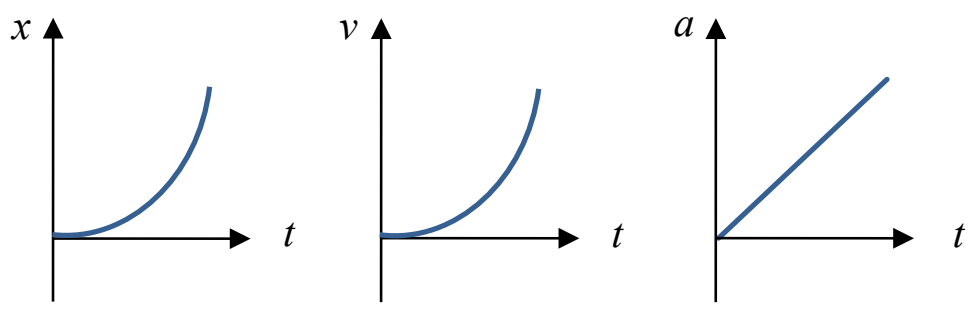

b)
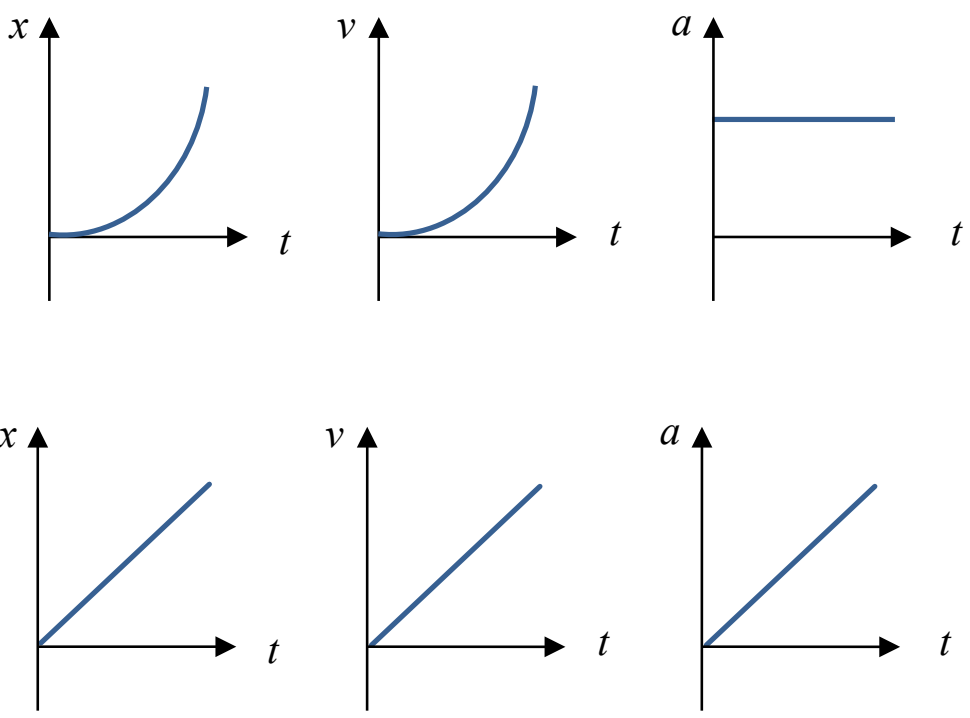

c)
"The item has a constant acceleration and hence changes in position and speed are accelerating." (20\%)
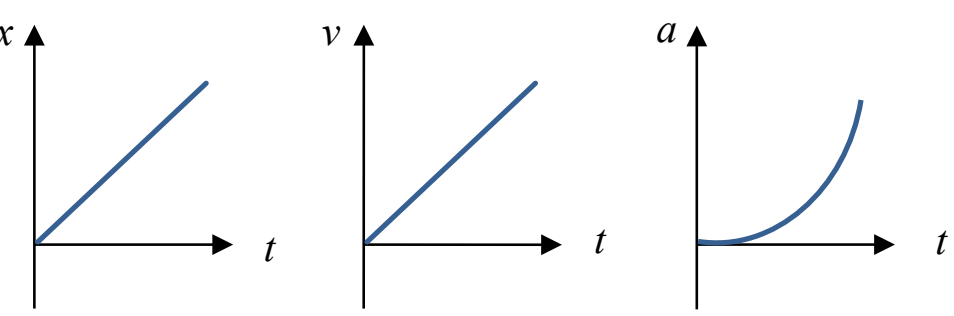

d)

Figure 3. Students' preconceptions about the motion of an item when the item falls freely. Other preconceptions were different combinations of these graphs. The percentage of the students who drew these particular combination of graphs and few selected verbal answers connected to the graphs are shown in the figures. $(N=61)$ 
Figure 4 shows an example of one video and its analysis made after the discussion of preconceptions. Figure $4 \mathrm{~b}$ shows a Tracker graph when scaling of coordinate axis was done automatically by Tracker. Obviously, students could interpret the graphs incorrectly, because the position and velocity graphs look very similar and the acceleration curve seems ambiguous if the scaling was ignored. At this point, the teacher should guide the students in the right direction. Students whose prediction was false were very confused and anxious about the scaling and the fluctuation of the measurement points. Thus, the measurement result shown in Tracker was not obvious for the students whose prior knowledge was not so high. On the other hand, students whose prior knowledge were higher solved the problem with axis scaling and understood the fluctuation of the measurement points as a natural consequence of measurement error. It was obvious that students enjoyed the studying of graphs depended on their prior knowledge level. If the time schedule was flexible, students should be encouraged to do several measurements and compare the results. For example, Figure $4 \mathrm{c}$ shows a typical result of the measurements where the measurement do not start from the very beginning. With this example students can learn how to determine the slope of a line if it does not go through origin (abovementioned misconception number 4). 


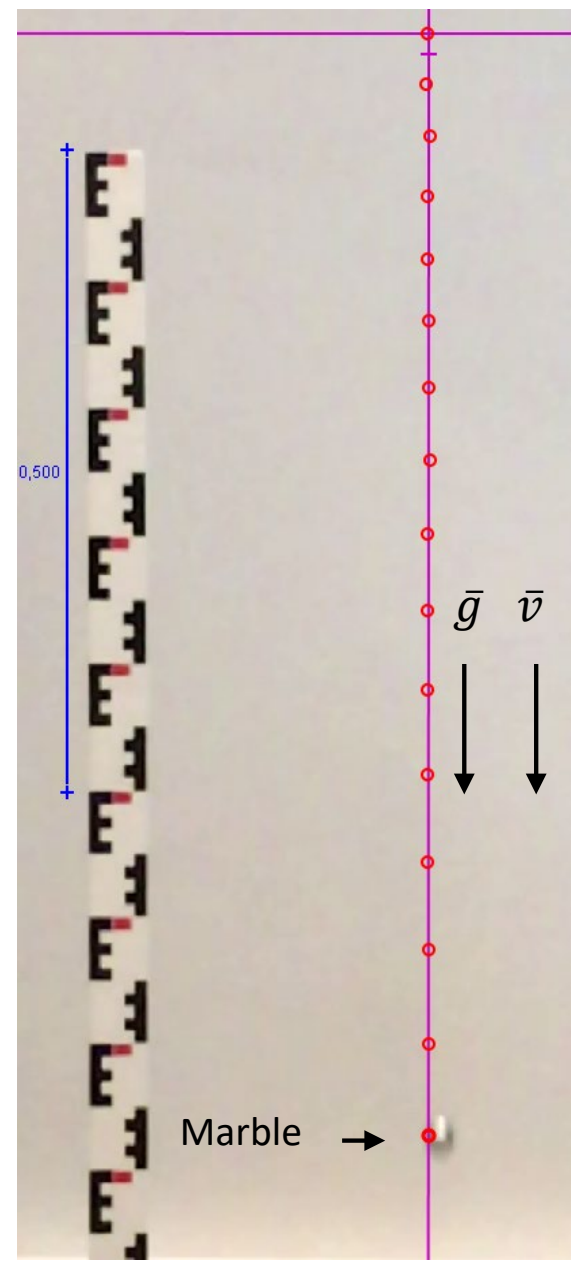

a)
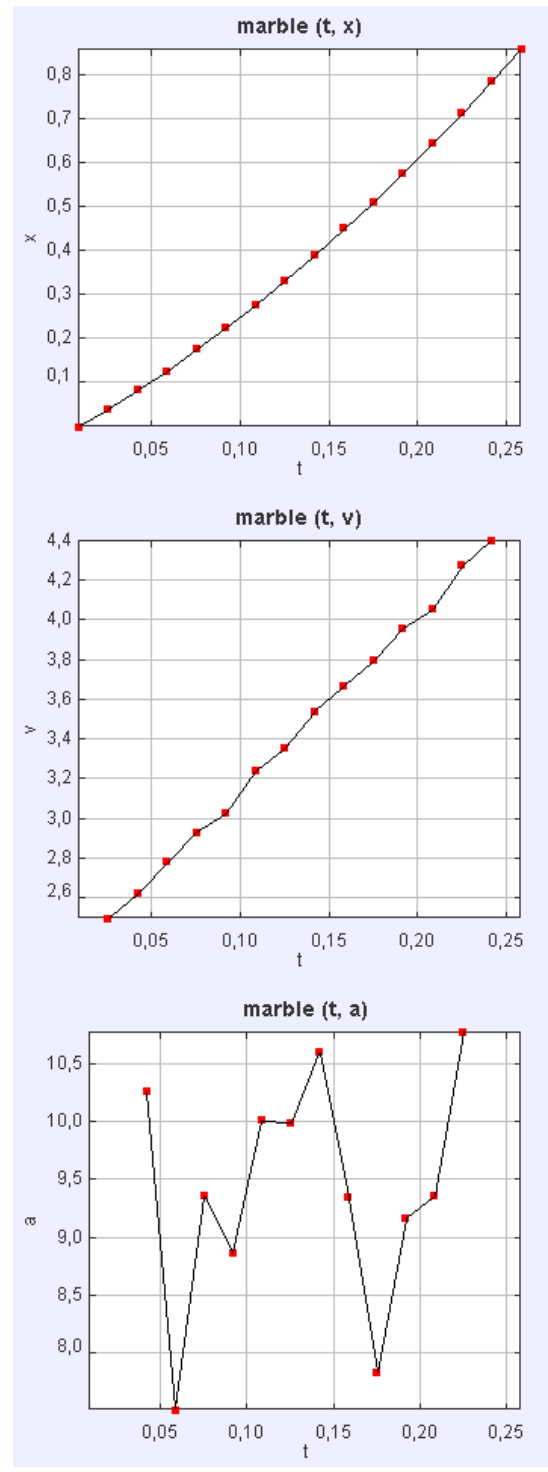

b)
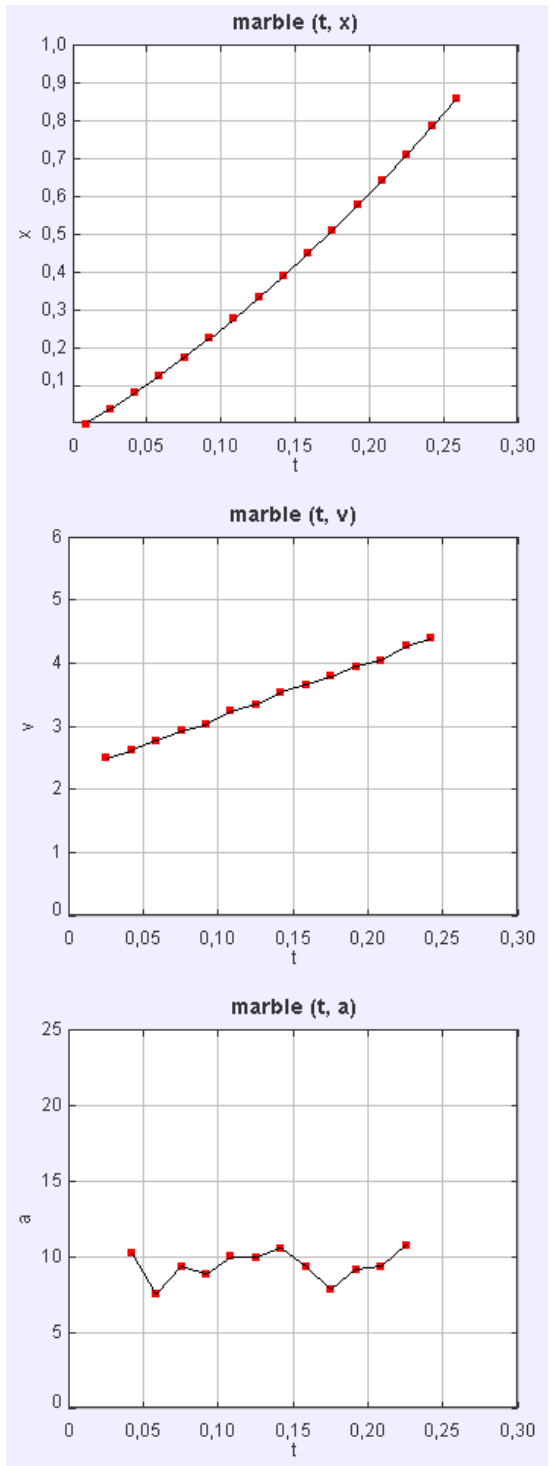

c)

Figure 4. a) A screenshot from a tracked video showing a freely falling marble. A ruler for calibration (blue 0,500 $\mathrm{m}$ ) and coordinate axes (purple) are set in the image. b) Graphs drawn by Tracker according to the tagged points: $(t, x)-,(t, v)$ - and $(t, a)$-graphs. The auto-scaling is unsuitable and the result is not obvious for the students. c) Same graphs as in figure b), but the scaling was adjusted manually. 
Besides the qualitative analysis students determined the gravitational acceleration from the graphs (about $10 \mathrm{~m} / \mathrm{s}^{2}$ ). The scientific explanation and students comments was discussed in the class together similarly as earlier, and some homework was given to deepen, broaden and apply the concepts covered in the class.

\subsection{Motion on an inclined plane}

When moving to the third measurement task, i.e. motion on an inclined air track experiments, the students' understanding of acceleration had clearly improved. Indeed, $57 \%$ of the students drew all the graphs perfectly correctly and incorrect acceleration graphs were only $35 \%$. This was a remarkable improvement over the previous tasks, but still $26 \%$ of the students responded that acceleration increases as the cart is moving. Students did not linked the motion on an inclined plane with the falling object experiment in their preview. Figure 5 presents the students' most popular preconceptions. Considering the misconceptions described by Beichner, it is seen in Figure 5a that some students still do not distinguish distance, velocity and acceleration and it is believed that graphs of these variables are identical as noted previously. 
a)

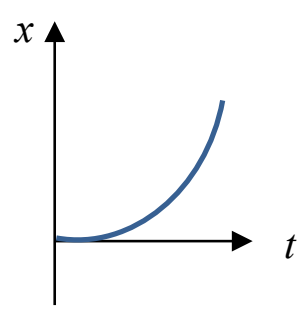

b)

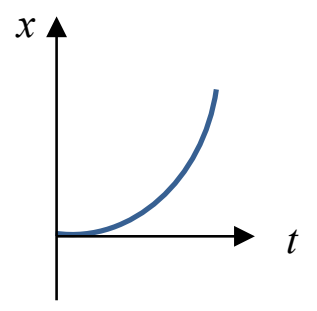

c)
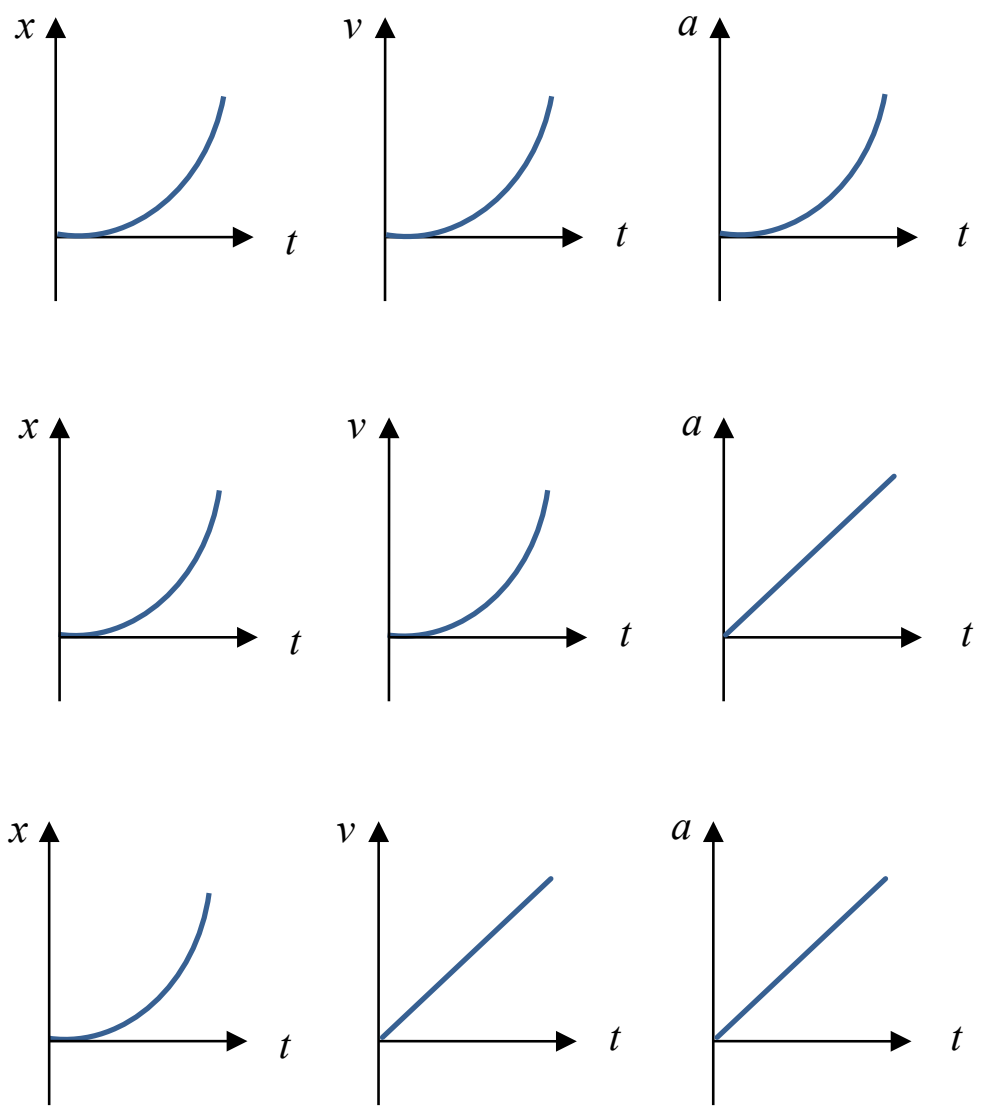

"All the quantities are rising sharply." (10\%)
"Acceleration is constantly increasing." (5 \%)
"Speed accelerates constantly." (5 \%) d)

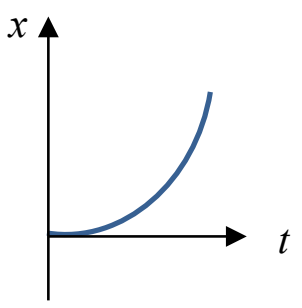

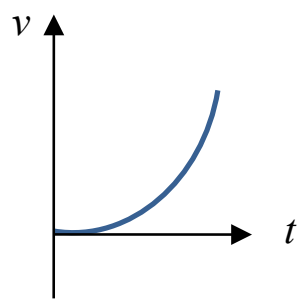

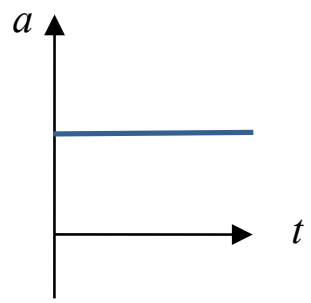

"Speed grows, acceleration is constant." (5\%)

Figure 5. Students' false assumptions on an accelerating cart on an inclined air track. Other false assumptions were different combinations of these graphs. The percentage of the students who drew these particular combination of graphs and few selected verbal answers connected to the graphs are shown in the figures. $(N=61)$

The students were eager to start the measurements because at this stage they had an idea how to proceed and the technical issues where familiar and group working where smooth. Figure 6 shows the experiment where the cart is moving on the inclined air track. Also in this case the axis scaling was very important aspect as in the case of last experiment. In Figure $6 \mathrm{~b}$ and $6 \mathrm{c}$ there are the same results with the different coordinate axis. If the time schedule flexible changing the angle for inclined plane and comparing the results for different measurements would be useful. 


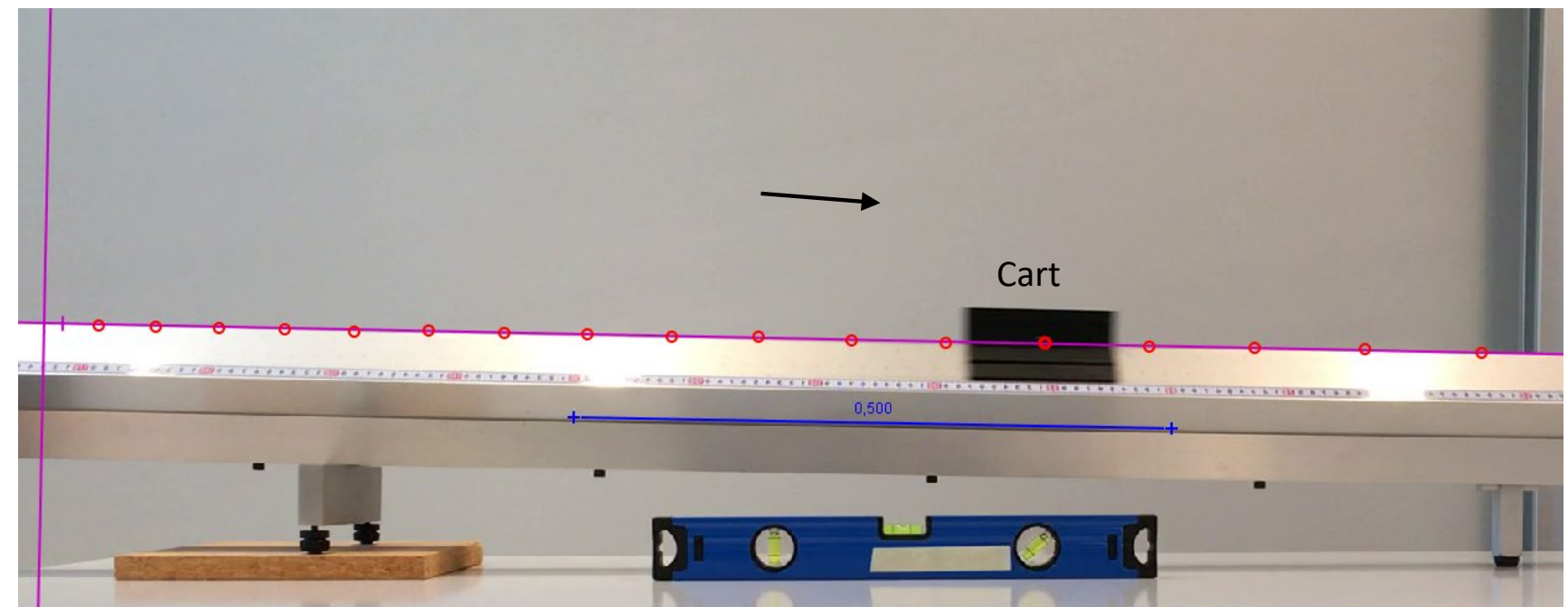

a)
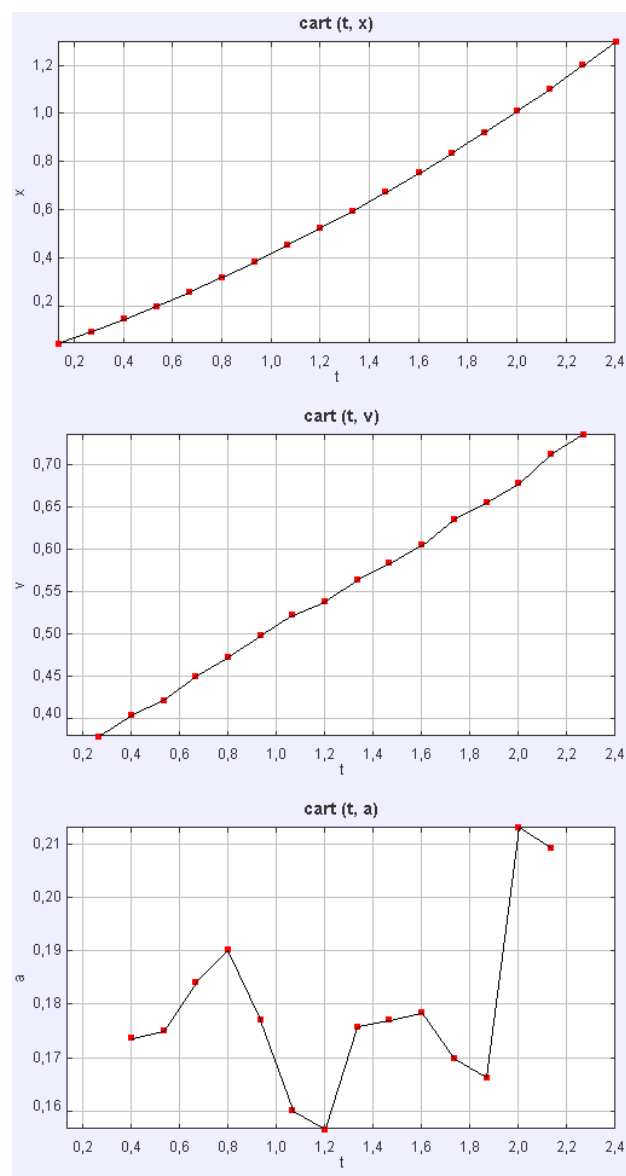

b)
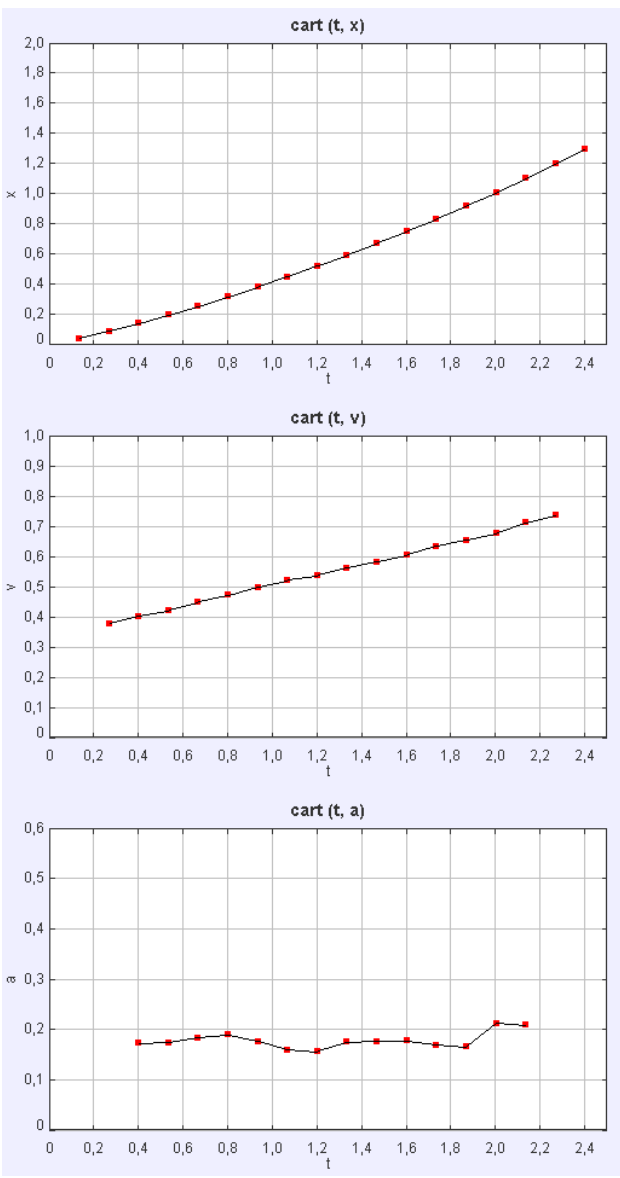

c)

Figure 6. a) A screenshot from a tracked video showing the cart moving on the inclined air track from left to right and the tagged marks. A coordinate system (purple) and a known distance (blue $0,500 \mathrm{~m}$ ) for the calibration are set in the image. b) The program drew position, velocity and acceleration graphs and scaled automatically the axis. c) More informative graphs after scaling the axes manually. 
Students who had no conflict between their preconceptions and the measurement results wrote some reflection about the results. They commented shortly on the results and gave some explanation for the graphs, as "There are a few inaccuracies in the measurements due to the imperfection of the measuring points." There were also a comment which stated that: "This time we did well. Our own preconception graphs are very similar to the measurements results." This suggests that students thought that if they preconceptions were consistent with the measurements they had succeeded, although it was emphasized repeatedly that the rightness of preconceptions is not evaluated. Only few students who had conflict with their results gave some verbal statements, for instance: “Acceleration was constant." It can be concluded that it was very hard for the students to give some verbal reflection.

\subsection{Projectile motion experiment}

The modeling of the projectile motion was not familiar to any of the students and this was reflected in the drawings of the students. The graphs were very varied and the typical answers could not be inferred. However, it was evident from the responses that some of the students were able to perceive that the projectile motion was divided into vertical and horizontal motions and that the horizontal motion could be modeled as a constant velocity motion.

Figure 7 gives couple of examples about the students' answers. Considering the misconceptions described by Beichner, it is seen in Figure $7 \mathrm{a}$, that some of the students do not still distinguish distance, velocity and acceleration. As in Figure $7 \mathrm{~b}$ students admitted that the task was very difficult, and in many case the drawings were hard to analyze. Figure 8 shows a projectile motion experiment result; the graphs in this example are quite easy to interpret. 
a)
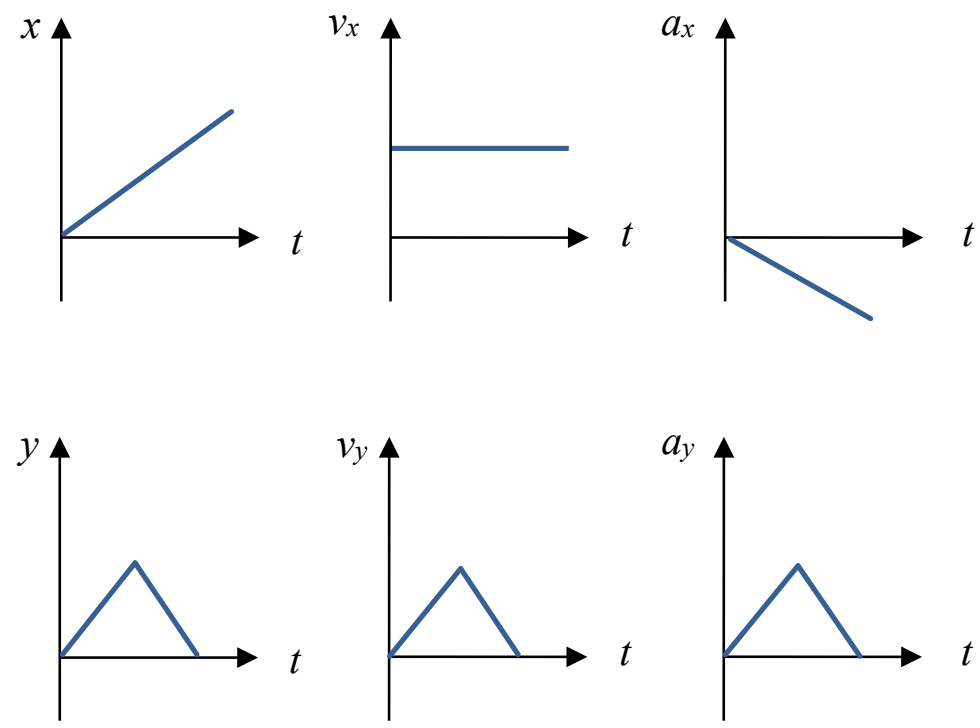

$a_{y}$

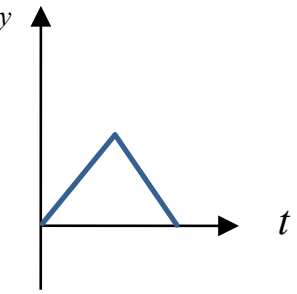

$v_{x}$
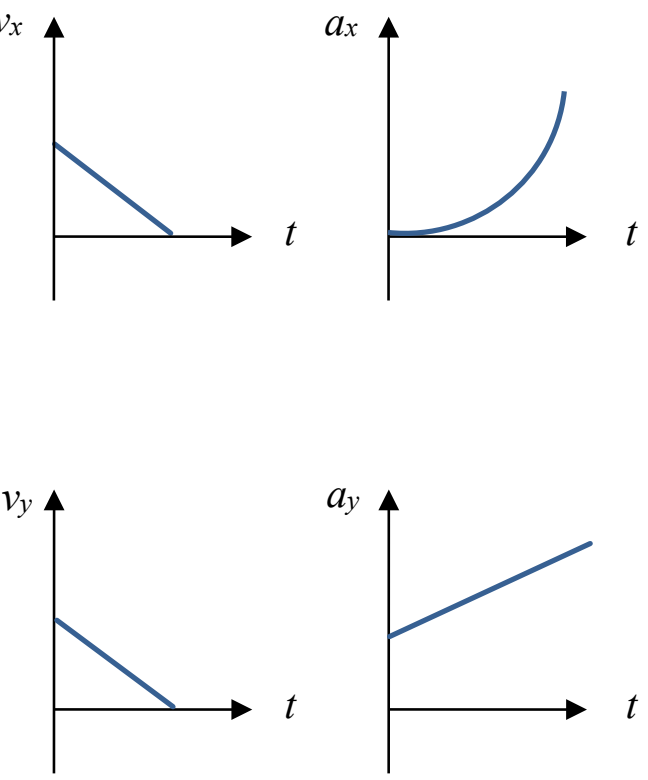

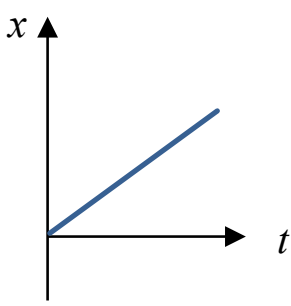

b)

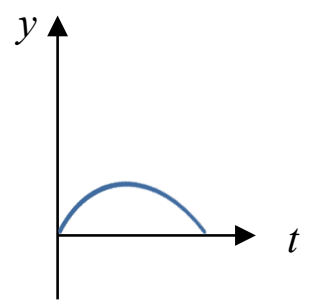

$a_{y}$

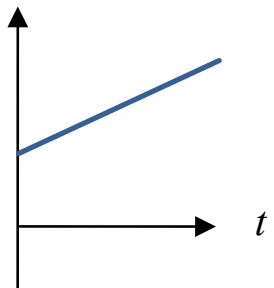

"Distance changes as constantly, speed is constant and acceleration decreases in $x$ direction. Acceleration increases and decreases in $y$ direction."
"It is difficult to find out the difference between $x$ and $y$ directions."

Figure 7. Students' preconceptions concerning the projectile motion: some combination of graphs drawn by the students and selected verbal answers connected to the graphs are shown in the figures. 
a)

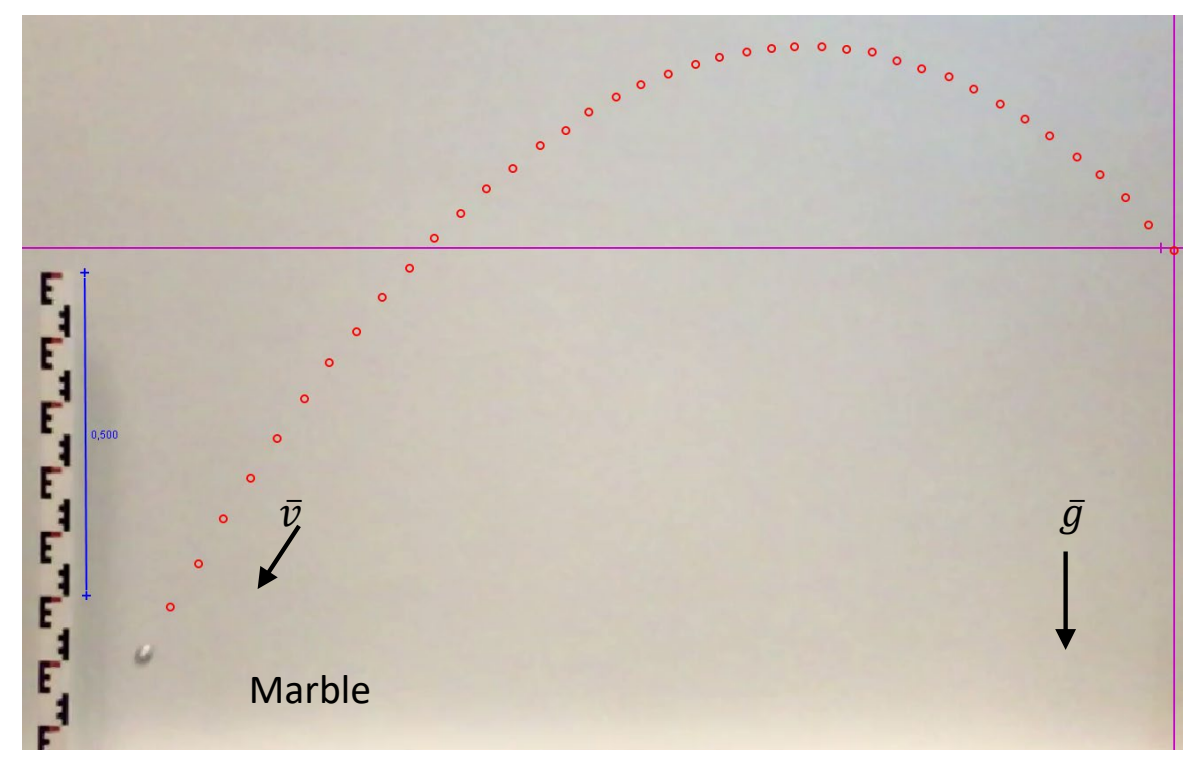

b)
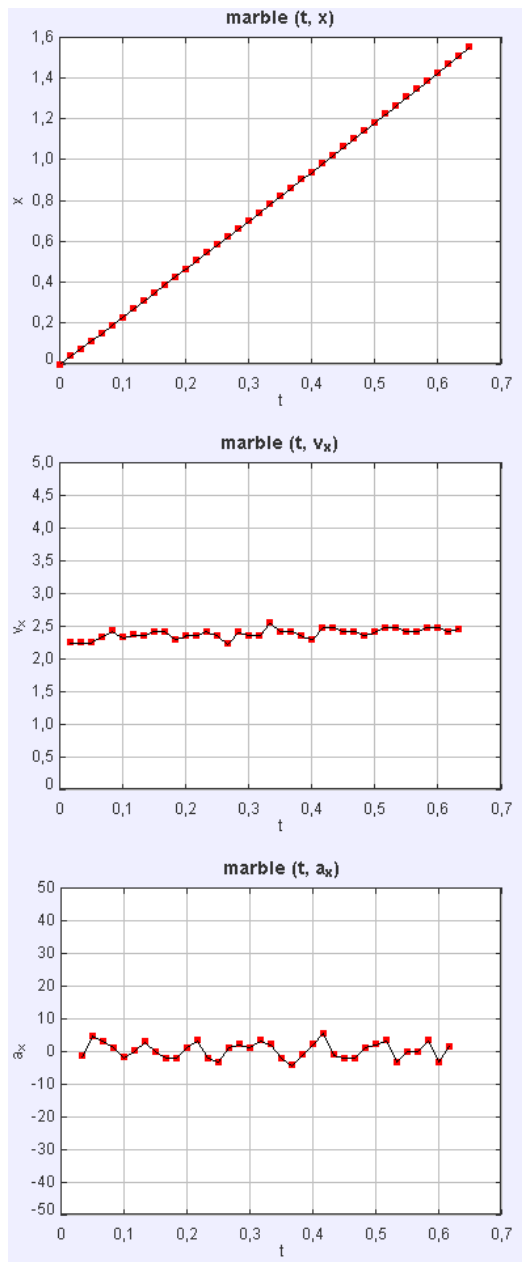

c)
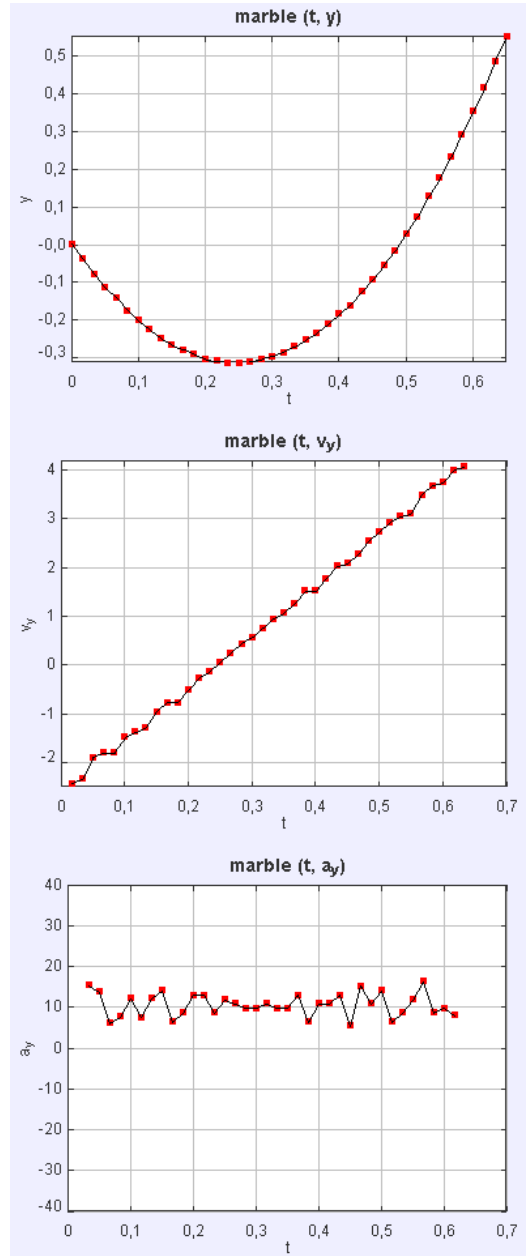

Figure 8. a) A screenshot from a tracked video showing motion trajectory for a small object (marble) thrown at an angle. A coordinate system (purple lines) and a known distance (blue $0,500 \mathrm{~m}$ ) for the calibration were set in the image. b) Position, velocity and acceleration graphs in $\mathrm{x}$ direction. c) Position, velocity and acceleration graphs in y direction. 
Worthwhile to mention that after the measurements students introduced ideas how to apply their learning in practice: e.g. $100 \mathrm{~m}$ running, swimming, etc. Thus, it was seen by the students that the video analysis and kinematic graphs were not just limited in the classroom or laboratory, but also valuable from the practical point of view.

\subsection{Learning gain evaluation by TUG-K results and normalized gain}

The results of the TUG-K before and after the measurements are shown in Figure 9. Figure 9 shows the question number from the test (Beichner, 1994) on the horizontal axis and the percentage of respondents with correct answer on the vertical axis before and after the measurements. In addition, Figure 9 shows Beichner's result with a larger sample $(\mathrm{N}=524)$.

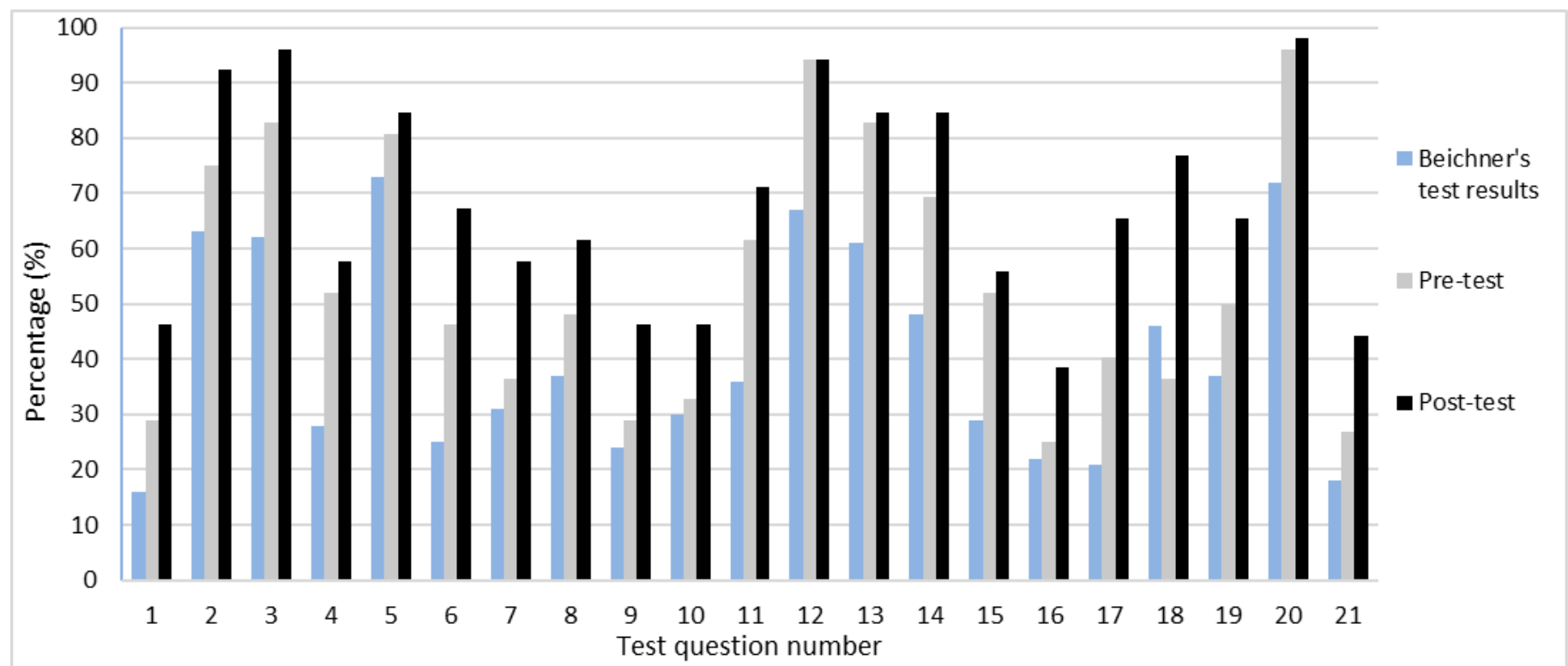

Figure 9. Results of the TUG-K. The figure shows the test question number on the horizontal axis and the percentage of the respondents with correct answer on the vertical axis. The figure shows the Beichner's test results (1994) as well as the results of this research before and after the lessons.

Naturally, the pre-results are generally improved as can be seen in Figure 9. However, according to the TUG-K questions 1, 4, 10, 16 defining the surface area from the graphs was still challenging for the students after the post-test, which is understandable, because the tasks on lessons did not specifically focus on that issue, although there were tasks related to area calculations in the homework. Although 
right answers concerning the questions 1, 10 and 16 increased quite remarkably, those still remained below $50 \%$. The result concerning the questions 4 had only a minor rise, and this states that students had difficulties before and after the measurements to calculate a distance from the area bounded by the line if the speed is not constant. The item 16, in which student had to calculate the speed of the time-acceleration graph with a triangular surface area, was considered the most difficult question. However, according to the question 20 almost all students were able to determine the distance from a graph by reading the constant speed value and multiplying it by time. In addition, the results concerning question 18 states that the students were able to qualitatively tell that the distance can be calculated from the surface area of the timespeed graph: after the measurements $77 \%$ answered correctly to this question, growth in real results was $40 \%$, which is a quite remarkable result.

The TUG-K results suggest that students' perception of acceleration and velocity had improved significantly, which was consistent with the perception we received on the workbooks. About 20 percentage points growth was observed in students' ability to calculate acceleration of time-speed graphs (items 2, 6, 7). At first, only about $50 \%$ of the students understood the link between the straight slope and the acceleration. After the measurements, more than $80 \%$ were able to associate the acceleration with the slope factor, although about $20 \%$ of them did not consider different degrees on the axes. According to items 5 and 13, a large number of students were able to calculate a positive slope, but according to item 17, not negative one. After the measurements, the students were able to calculate the speed also from the negative slope: the increase was 25 percentage points in item 17 .

To reveal difference between the experimental groups and the control group taught by lecturing, we calculated the normalized gain to both groups using Formula 1. The result to the experimental and the control groups were very similar: $g=0.30$ to the experimental group and 0.26 to the control group. Thus, according to the TUG-K results the students learned to interpret graphs at least as well as with the lecture method.

\section{Conclusions}

A very important part of the objectives in an undergraduate science course is that students learn to draw and interpret graphical presentations. In this work we utilized POE based learning method mediated by a video analysis software in order to improve 
the understanding of kinematic graphs. According to the TUG-K results and the workbook presentations of students we found that first year engineering students had great challenges and difficulties with interpreting graphical presentations in kinematics. Although the understanding of the kinematic graphs and velocity and acceleration concepts improved, naturally, some misconceptions of students were quite resilient and were not overcome. It was also found that students had very serious challenges to reflect the measurements and results in verbal form, as Explain stage of POE method demands to resolve the cognitive conflict produced between the Prediction and Observation stages.

These difficulties suggest that just four experiments is not enough regardless the use of an active methodology associated with video analysis. Likely, a longer-term plan including more experiments, i.e. students reproduce the same graphs, but in slightly different situations, could help students to reflect on graphs interpretation. For example, a vertical launching upward, an inclined plane with upward motion and a horizontal launching separated of an oblique launching, may be simple and instructive experiments to reinforce the students' understanding of scientific concepts and kinematics graphs.

The quantitative analysis performed through TUG-K showed a small, but relevant, learning gain when considering specific themes. In fact, the quantitative results, although modest in a global perspective, improved significantly in specific topics, such as understanding of the meaning of positive and negative slope in kinematic graphs as well as the relationship between area and displacement in velocity-time graph. In general, this research indicates that a teaching program based on the POE methodology mediated by the Tracker software has a good potential to promote the learning of kinematics in undergraduate engineering classes.

\section{References}

Arons, A. B. (1993). Guiding insight and inquiry in the introductory physics laboratory. The Physics Teacher, 31(5), 278-282.

Beichner, R. (1994). Testing student interpretation of kinematics graphs. American Journal of Physics, 62, 750-762.

Champagne, A., Klopfer, L., \& Anderson, J. (1980). Factors influencing the learning of classical mechanics. American Journal of Physics, 48(12), 1074-1079.

Chase, C. C., Shemwell J. T., \& Schwartz, D. L. (2010). Explaining across contrasting cases for deep understanding in science: An example using interactive simulations. ICLS, 1.

Crouch, C., Fagen, A. P., Callan, J. P., \& Mazur, E. (2004). Classroom demonstrations: Learning tools or entertainment? American Journal of Physics, 72(6), 835-838. 
De Jesus, V. L. (2017). Experiments and video analysis in classical mechanics. Series: Undergraduate Lecture Notes in Physics. Springer.

Haake, R. (1998). Interactive-engagement versus traditional methods: A six-thousand-student survey of mechanics test data for introductory physics courses. American Journal of Physics, 66, 64.

Haysom, J., \& Bowen, M. (2010). Predict, observe, explain - activities enhancing scientific understanding. NSTA Press.

Hodson, D. T. (1988). Towards a philosophically more valid science curriculum. Science Education, 72(1), 19-40.

Hofstein, A., \& Lunetta, V. (2004). The Laboratory in Science Education: Foundations for the Twenty-First Century. Science Education, 88, 28-54.

Holmes, N.G., Olsen, J., Thomas, J.L., \& Wieman, C.E. (2017). Value added or misattributed? A multi-institution study on the educational benefit of labs for reinforcing physics content. Physical Review Physics Education Research, 13(1), 1-12.

Hussain, N. H., Ali, R., Haron, H. N., Radin Salim, K., \& Hussain, H. (2013). Predict-observeexplain tasks using simulation to assist students' learning in basic electric circuits. Proceedings of the IETEC'13 Conference, Ho Chi Minh City, Vietnam.

Kearney, M. (2004). Classroom use of multimedia supported predict-observe-explain tasks in a social constructivist learning environment. Research in Science Education. 34(4), 427-453.

Physlets. (2018). Tracker Video analysis and modeling tool. Retrieved 17/03/2017from http://physlets.org/tracker/

Physport. (2019). Supporting physics teaching with research-based resources. Retrieved 15/01/2019 from https://www.physport.org/assessments/assessment.cfm?I=6\&A=TUGK

Piaget, J. (1985). Equilibration of cognitive structures: The central problem of intellectual development. University of Chicago Press.

Tamir, P. (1989). Training teachers to teach effectively in the laboratory. Science education, 73(1), 59-69.

Tamir, P. (1991). Practical work at school: An analysis of current practice. In B. Woolnough (Ed.) Practical Science. Milton Keynes: Open University Press.

Tao, P. K., \& Gunstone, R. F. (1999). A process of conceptual change in force and motion during computer-supported Physics instruction. Journal of Research in Science Teaching, 36(7), 859-882.

Trowbridge, D. E., \& McDermott, L. C. (1980). Investigation of student understanding of the concept of velocity in one dimension. American journal of Physics, 48, 1020-1028.

Trowbridge, D. E., \& McDermott, L. C. (1981). Investigation of student understanding of the concept of acceleration in one dimension. American journal of Physics, 49, 242-253.

Zavala, G., Tejeda, S., Barniol, B., \& Beichner, R. J. (2017). Modifying the test of understanding graphs in kinematics. Physical Review Physics Education Research, 13, 020111.

Whitaker, R. J. (1983). Aristotle is not dead: Student understanding of trajectory motion. American Journal of Physics, 51, 352-357.

White, R., \& Gunstone, R. (1992). Probing Understanding. The Falmer Press. 